\title{
High feeding intensity increases the severity of fatty liver in the American mink (Neovison vison) with potential ameliorating role for long-chain n-3 polyunsaturated fatty acids
}

Morag F Dick', Jennifer Hurford', Sha Lei ${ }^{1,2}$, Anne-Mari Mustonen ${ }^{3,4}$, Petteri Nieminen ${ }^{3,4}$ and Kirsti Rouvinen-Watt ${ }^{1 *}$

\begin{abstract}
Background: Rapid body fat mobilization, obesity, and an inadequate supply of n-3 polyunsaturated fatty acids (PUFA) have been suggested to play roles in the etiology of fatty liver in the American mink (Neovison vison). This study examined the effects of feeding intensity and dietary fat source on fatty liver induced by fasting. In a multi-factorial design, 3 different fat sources (herring oil, rich in n-3 PUFA, soya oil, rich in n-6 PUFA, and canola oil, rich in n-9 monounsaturated fatty acids) were fed to mink at a low and high feeding intensity for 10 weeks, followed by an overnight or a 5-day fasting treatment to induce fatty liver.

Results: Fasting led to the development of fatty liver with increased severity in the mink fed at the high feeding intensity. The herring oil diet, high in long-chain n-3 PUFA, was found to decrease the severity of fatty liver in the mink at the high feeding intensity.

Conclusion: Preventing excessive weight gain and increasing dietary intake of n-3 long-chain PUFA may help prevent excessive lipid accumulation during prolonged periods of fasting or inappetence by promoting hepatic fatty acid oxidation.
\end{abstract}

Keywords: Fasting, Fatty liver, Mink, Obesity, Polyunsaturated fatty acids

\section{Background}

Fatty liver syndrome is a common metabolic disease in farmed American mink (Neovison vison) and it has been reported to develop during acute stressful periods, when mink may show a loss in appetite for a few days [1]. Hepatic fatty infiltration is also a common pathological finding in female mink with nursing sickness [2]. Experimentally, food withdrawal has been used to model the development of the disease, with hepatic lipid accumulation occurring in less than 5 days of fasting [3]. Food deprivation can also result in borderline steatohepatitis in a closely related species, the European polecat (Mustela putorius) [4]. Studies using the mink model have shown that fat depots, particularly intra-abdominal, are readily mobilized during fasting

\footnotetext{
* Correspondence: kirsti.rouvinen-watt@dal.ca

'Department of Plant and Animal Sciences, Faculty of Agriculture, Dalhousie University, P.O. Box 550, B2N 5 E3 Truro, NS, Canada

Full list of author information is available at the end of the article
}

and there is selective mobilization of $\mathrm{n}-3$ polyunsaturated fatty acids (PUFA) from the adipose tissue and depletion in the liver [5]. This suggests that causative factors in mustelid fatty liver could be the rapid mobilization of body fat during fasting, obesity, and loss of n-3 PUFA, with similarities to human non-alcoholic fatty liver disease and feline hepatic lipidosis $[3,4,6]$.

Excessive body fat is a common risk factor for fatty liver in both mink and cats (Felis catus) [1,7], and it is correlated with the severity of fatty liver in humans [8]. Increased adiposity in mink can lead to elevated blood glucose levels and the development of hyperinsulinemia [9]; derangements which, in humans, are associated with the severity of hepatic steatosis [10]. Furthermore, increased adiposity may increase circulating levels of free fatty acids (FFA) and subsequently the quantity of FFA the liver is exposed to $[11,12]$. 
The composition of dietary fats may also influence fatty liver, with an association of low proportions of n-3 PUFA or a high n-6:n-3 PUFA ratio with hepatic lipid accumulation [13]. The long-chain n-3 PUFA, 20:5n-3 and 22:6n-3, are suggested to be the most effective in preventing or ameliorating the development of fatty liver [14-17]. Within the liver, increasing long-chain n-3 PUFA may alter the balance between fatty acid oxidation and lipid secretion $v s$. de novo lipogenesis, and thereby reduce overall lipid accumulation [2]. This could make dietary fat an important consideration for mink as they are probably unable to sufficiently synthesize the long-chain n-3 and n-6 PUFA from their precursors [18].

Fatty liver disease in mink is initially asymptomatic and develops rapidly to the severe stages, thus the focus needs to be on preventative measures rather than treatment. Studies have examined the effect of diet on hepatic lipid content under normal physiological conditions [18] and the relationship between body fat and hepatic lipid content in fasted mink [19], but neither has been investigated directly during the development of fatty liver. The aim of this study was to examine how feeding intensity (FI) and dietary fat sources varying in $n-3$ and n-6 PUFA affect the development of fasting-induced fatty liver in mink.

\section{Methods}

Seventy-two standard black five-month-old mink (36 male, 36 female) were used at the Canadian Centre for Fur Animal Research (Truro, NS). The mink were housed individually in pens $(\mathrm{W} \times \mathrm{H} \times \mathrm{L}: 30 \mathrm{~cm} \times 45 \mathrm{~cm} \times 75 \mathrm{~cm})$ with wood chip-bedded nest boxes. The study was carried out in accordance with the Canadian Council on Animal Care [20] and approval of the Animal Care and Use Committee of the Dalhousie University, Faculty of Agriculture (formerly Nova Scotia Agricultural College, Truro; Permit ACUC\#2007-041).

In this multi-factorial study, each mink was assigned to an experimental diet containing herring oil (HO), soya oil (SO), or canola oil (CO) as the dietary fat source (Tables 1 and 2), and the diets were formulated to meet the nutritional recommendations for mink [21]. Fatty acid profiles of the diets were analyzed using gas-liquid chromatography (GC-FID and GC-MS, $6890 \mathrm{~N}$ network GC-system, Agilent Technologies Inc., Palo Alto, CA) [22]. Each diet was fed either at a low feeding intensity (LFI) of $80 \%$ recommended dietary allowance (RDA) or a high feeding intensity (HFI) of 120\% RDA, with the RDA adjusted for sex, month, and metabolic body weight $\left(\mathrm{BW}^{0.75} \mathrm{~kg}\right)$ [21]. BW and feed intake were measured monthly over a three-day period by determining the amount of feed left uneaten.

After feeding the dietary regimes for 10 weeks, the mink were divided further into two groups, the control group which was fasted overnight and the fasted group which
Table 1 Ingredient formulation of the herring oil, soya oil, and canola oil experimental diets

\begin{tabular}{lccc}
\hline & \multicolumn{3}{c}{ Diet } \\
\cline { 2 - 4 } Ingredient, $\boldsymbol{g} / \mathbf{k g}$ & Herring oil & Soya oil & Canola oil \\
\hline Cod racks & 525 & 525 & 525 \\
Pork liver & 135 & 135 & 135 \\
Pork spleen & 70 & 70 & 70 \\
Extruded barley & 144 & 144 & 144 \\
Corn gluten meal & 31 & 31 & 31 \\
Herring oil & 47 & - & - \\
Soya oil & - & 47 & - \\
Canola oil & - & - & 47 \\
Vitamin mineral premix & 4 & 4 & 44 \\
Water & 44 & 44 & 47
\end{tabular}

${ }^{a}$ Vitamin Mineral Premix growing/furring [(concentration/purity), amount per tonne of premix]: vitamin A $\left(600 \times 10^{5} \mathrm{IU} / \mathrm{kg}\right), 600 \mathrm{IU}$; vitamin $\mathrm{D}\left(500 \times 10^{5}\right.$ $\mathrm{IU} / \mathrm{kg}), 600 \mathrm{IU}$; vitamin E (500 $000 \mathrm{lU} / \mathrm{kg}), 150 \mathrm{IU}$; vitamin $\mathrm{K}(33 \%), 0.66 \mathrm{~g}$; vitamin C (97.5\%), $94.6 \mathrm{~g}$; riboflavin (95\%), $47.5 \mathrm{~g}$; DL Ca-pantothenate (45\%), $6.30 \mathrm{~g}$; niacin (99\%), $19.8 \mathrm{~g}$; vitamin $\mathrm{B}_{12}(1000 \mathrm{mg} / \mathrm{kg}), 0.02 \mathrm{~g}$; folic acid (3\%), $0.45 \mathrm{~g}$; biotin (2\%), $0.1 \mathrm{~g}$; choline chloride $(60 \%), 600 \mathrm{~g}$; thiamine $(97 \times$ $\left.10^{4} \mathrm{mg} / \mathrm{kg}\right), 3.88 \mathrm{~g}$; pyridoxine $\left(99 \times 10^{4} \mathrm{mg} / \mathrm{kg}\right), 4.95 \mathrm{~g}$; manganous oxide (60\%), $10.8 \mathrm{~g}$; zinc oxide (80\%), $30.4 \mathrm{~g}$; cupric sulphate (25\%), $5 \mathrm{~g}$; cobalt carbonate (45\%), $0.45 \mathrm{~g}$; selenium premix ( $675 \mathrm{mg} / \mathrm{kg}), 0.22 \mathrm{~g}$; ferrous sulphate (27\%), $99.9 \mathrm{~g}$; ground limestone (38\%), $190 \mathrm{~g}$; ethoxyquin (50\%), $45 \mathrm{~g}$; wheat middlings $3324 \mathrm{~g}$.

was deprived of food for a 5-day period. Following the fasting treatments, the mink were anaesthetized with intramuscular injection of xylazine $(3.4 \mathrm{mg} / \mathrm{kg} \mathrm{BW})$ and ketamine hydrochloride $(8.5 \mathrm{mg} / \mathrm{kg} \mathrm{BW})$. A blood sample was taken by cardiac puncture (Vacutainer ${ }^{\odot}$ EDTA tubes) and the mink were killed using an intra-cardiac injection of pentobarbital sodium (106 mg/kg BW). Immediately following euthanasia, a liver sample was flash frozen in liquid nitrogen and stored at $-80^{\circ} \mathrm{C}$ for later lipid extraction using the Folch method [23]. Hepato-somatic index (HSI) was calculated as follows: (liver weight, $\mathrm{g} / \mathrm{BW}, \mathrm{g}) \times 100$.

During the feeding trial, blood glucose measurements were taken postprandially using the Accu-Check Compact ${ }^{\mathrm{TM}}$ blood glucose monitor (Roche Diagnostics, Laval, QC). Clinical chemistry analyses were carried out on plasma (stored at $-80^{\circ} \mathrm{C}$ ) for urea, glucose, alanine transaminase (ALT), and alkaline phosphatase (AKPH) at the Diagnostic Services Laboratory of the Atlantic Veterinary College (Charlottetown, PEI). Further analyses were performed at the University of Eastern Finland (Joensuu, Finland) for plasma levels of triacylglycerols (TAG), low-density lipoprotein (LDL) and high-density lipoprotein (HDL) cholesterol, and FFA as outlined by Mustonen et al. [5]. Plasma concentrations of insulin, leptin, triiodothyronine $\left(\mathrm{T}_{3}\right)$, and thyroxine $\left(\mathrm{T}_{4}\right)$ were determined using established validated methodology according to Mustonen et al. [24].

Statistical analysis was carried out using the Proc Mixed in SAS v.9 (SAS Institute Inc., Cary, NC) to determine significant effects and interactions, and significant differences 
Table 2 Nutrient composition and fatty acid profiles of the herring oil, soya oil, and canola oil experimental diets

\begin{tabular}{|c|c|c|c|c|}
\hline & & \multicolumn{3}{|c|}{ Experimental diet } \\
\hline & & Herring oil & Soya oil & Canola oil \\
\hline Composition & $n$ & 3 & 3 & 3 \\
\hline \multirow[t]{6}{*}{ (as fed) } & Dry Matter, \% & $39.1 \pm 0.7$ & $39.8 \pm 0.9$ & $39.5 \pm 0.5$ \\
\hline & Crude Protein, \% & $15.1 \pm 0.3$ & $15.6 \pm 0.5$ & $14.8 \pm 0.3$ \\
\hline & Crude Fat, \% & $6.7 \pm 0.4$ & $7.7 \pm 0.9$ & $6.5 \pm 0.5$ \\
\hline & Carbohydrate, \% & $12.5 \pm 0.8$ & $13.5 \pm 1.2$ & $13.86 \pm 0.5$ \\
\hline & Ash, \% & $4.0 \pm 0.2$ & $3.8 \pm 0.2$ & $3.8 \pm 0.3$ \\
\hline & $\mathrm{ME}^{1}, \mathrm{~kJ} / \mathrm{kg}$ & $6364 \pm 100$ & $6904 \pm 301$ & $6414 \pm 117$ \\
\hline Fatty acid profile, & Total SFA & $25.7 \pm 0.5^{\mathrm{A}}$ & $20.4 \pm 0.4^{B}$ & $14.9 \pm 0.5^{C}$ \\
\hline \multirow[t]{11}{*}{ molar\% } & $18: 1 n-9+11$ & $10.6 \pm 0.5^{c}$ & $17.4 \pm 0.4^{B}$ & $48.3 \pm 0.5^{\mathrm{A}}$ \\
\hline & $22: 1 n-11$ & $17.34 \pm 0.05^{\mathrm{A}}$ & $0.13 \pm 0.03^{B}$ & $0.08 \pm 0.01^{C}$ \\
\hline & Total MUFA & $53.17 \pm 0.29^{A}$ & $20.99 \pm 0.29^{B}$ & $53.85 \pm 0.29^{\mathrm{A}}$ \\
\hline & $18: 2 n-6$ & $8.86 \pm 0.08^{C}$ & $45.98 \pm 0.08^{\mathrm{A}}$ & $21.18 \pm 0.02^{B}$ \\
\hline & $20: 4 n-6$ & $1.47 \pm 0.13$ & $1.23 \pm 0.13$ & $1.08 \pm 0.13$ \\
\hline & Total n-6 PUFA & $10.83 \pm 0.55^{C}$ & $47.56 \pm 0.55^{\mathrm{A}}$ & $22.61 \pm 0.55^{B}$ \\
\hline & $18: 3 n-3$ & $0.75 \pm 0.14^{C}$ & $8.12 \pm 0.14^{\mathrm{A}}$ & $6.65 \pm 0.14^{B}$ \\
\hline & $20: 5 n-3$ & $4.05 \pm 0.07^{A}$ & $0.82 \pm 0.07^{B}$ & $0.54 \pm 0.07^{C}$ \\
\hline & $22: 6 n-3$ & $3.40 \pm 0.18^{\mathrm{A}}$ & $1.52 \pm 0.18^{B}$ & $1.03 \pm 0.18^{B}$ \\
\hline & Total n-3 PUFA & $10.29 \pm 0.29^{A}$ & $10.97 \pm 0.29^{A}$ & $8.57 \pm 0.29^{B}$ \\
\hline & $n-6: n-3$ PUFA & $1.05 \pm 0.03^{C}$ & $4.35 \pm 0.03^{A}$ & $2.63 \pm 0.03^{B}$ \\
\hline
\end{tabular}

Values are Ismeans \pm SEM. Labeled means with no common letters differ within row $(P \leq 0.05)$. Metabolizable energy, ME; monounsaturated fatty acids, MUFA; polyunsaturated fatty acids, PUFA; saturated fatty acids, SFA.

${ }^{1} \mathrm{ME}$ was calculated as the sum of each of the energy nutrients multiplied by their digestibility coefficients and energy values [(crude protein $\left.\times 0.85 \times 18.8 \mathrm{~kJ} / \mathrm{g}\right)+$ (crude fat $\times 0.90 \times 39.8 \mathrm{~kJ} / \mathrm{g}$ ) + (carbohydrate $\times 0.70 \times 17.6 \mathrm{~kJ} / \mathrm{g}$ )].

within these interactions. The monthly BW, feed intake, and blood glucose levels were analyzed using a split-plot design, with the repeated measures option. A split-splitplot design was used for the final blood analyses. To simplify analysis, in cases of a 3-way interaction that included fasting as an effect or a 4-way interaction, comparisons were made within the control and fasted mink, and between the individual control and fasted treatments only. The Pearson's correlation coefficients $\left(r_{p}\right)$ were calculated using SAS v.9. $\mathrm{P} \leq 0.05$ was considered statistically significant and the P-values are included in the online additional documentation (Additional files 1, 2 and 3). Results are presented as lsmeans \pm SEM.

\section{Results}

Feed intake and body weights

Feed intake was higher in the males compared to the females $(1452 \pm 25 \mathrm{~kJ} /$ day and $84.1 \pm 1.5 \mathrm{~g} \mathrm{DM} /$ day $v s$. $1038 \pm 25 \mathrm{~kJ} /$ day and $60.0 \pm 1.5 \mathrm{~g} \mathrm{DM} /$ day). The mink fed at the LFI had a constant feed intake of $80 \%$ RDA throughout the trial, while intake increased in the HFI group over time, reaching 103\% RDA at the end of the trial (Table 3). Diet also influenced feed intake, with increased caloric consumption from October to November only in the HO group.

During the feeding trial, both sexes lost weight when fed at the LFI, however, in the HFI group, only males exhibited significant weight gain (Table 4). The feeding trial resulted in two distinct BW groups in both sexes.

Table 3 Feed intake of the mink fed at the LFI and HFI and fed the herring oil, soya oil, and canola oil experimental diets during the feeding trial period

\begin{tabular}{|c|c|c|c|c|}
\hline & \multirow{2}{*}{\multicolumn{2}{|c|}{$\begin{array}{c}\text { Feed intake, } k J / \text { day } \\
\text { Feeding intensity }\end{array}$}} & \multirow{2}{*}{\multicolumn{2}{|c|}{$\begin{array}{c}\text { Feed intake, } \% \text { RDA } \\
\text { Feeding intensity }\end{array}$}} \\
\hline & & & & \\
\hline & LFI & HFI & LFI & $\mathrm{HFI}$ \\
\hline October & $1147 \pm 33^{\mathrm{Ab}}$ & $1223 \pm 37^{\mathrm{Ba}}$ & $80 \pm 2^{\mathrm{Ab}}$ & $89 \pm 2^{\text {Ba }}$ \\
\hline \multirow[t]{4}{*}{ November } & $1114 \pm 29^{\mathrm{Ab}}$ & $1495 \pm 29^{\mathrm{Aa}}$ & $80 \pm 1^{\mathrm{Ab}}$ & $103 \pm 1^{\mathrm{Aa}}$ \\
\hline & \multicolumn{3}{|c|}{ Feed intake, $k J / d a y$} & \\
\hline & \multicolumn{3}{|c|}{ Diet } & \\
\hline & Herring oil & Soya oil & Canola oil & \\
\hline October & $1193 \pm 45^{B}$ & $1196 \pm 45$ & $1164 \pm 45$ & \\
\hline November & $1461 \pm 36^{\mathrm{Aa}}$ & $1285 \pm 36^{b}$ & $1160 \pm 36^{c}$ & \\
\hline
\end{tabular}

Values are Ismeans \pm SEM. Labeled means with no common capital letters differ within the column, and means with no common lowercase letters differ within the row $(P \leq 0.05)$. High feeding intensity, $\mathrm{HFl}$; low feeding intensity, LFl; recommended dietary allowance, RDA. 
Table 4 Mink body weight during the feeding trial, at the end of the fasting period, and final body weight and liver weight at sampling

\begin{tabular}{|c|c|c|c|c|c|c|c|}
\hline & & \multicolumn{6}{|c|}{ Body weight during feeding trial, $g$} \\
\hline & & \multicolumn{6}{|c|}{ Sex $\times$ feeding intensity interaction } \\
\hline & & \multicolumn{3}{|c|}{ Male } & \multicolumn{3}{|c|}{ Female } \\
\hline & & LFI & \multicolumn{2}{|c|}{ HFI } & LFI & \multicolumn{2}{|c|}{$\mathrm{HFI}$} \\
\hline & Sep 27 & $2381 \pm 47^{\mathrm{A}}$ & \multicolumn{2}{|c|}{$2376 \pm 47^{B}$} & $1271 \pm 47^{\mathrm{A}}$ & \multicolumn{2}{|c|}{$1287 \pm 47$} \\
\hline & Oct 25 & $2283 \pm 47^{B^{*}}$ & \multicolumn{2}{|c|}{$2511 \pm 47^{A}$} & $1202 \pm 47^{B^{*}}$ & \multicolumn{2}{|c|}{$1326 \pm 47$} \\
\hline & Nov 22 & $2072 \pm 47^{C^{*}}$ & \multicolumn{2}{|c|}{$2528 \pm 47^{A}$} & $1096 \pm 47^{C^{*}}$ & \multicolumn{2}{|c|}{$1324 \pm 47$} \\
\hline & & \multicolumn{6}{|c|}{ Body weights during the 5-day fasting period, $g$} \\
\hline & & \multicolumn{3}{|c|}{ Feeding intensity } & \multicolumn{3}{|c|}{ Sex } \\
\hline & & LFI & \multicolumn{2}{|c|}{$\mathrm{HFI}$} & Male & \multicolumn{2}{|c|}{ Female } \\
\hline & 24-hour fasting & $1411 \pm 64^{C}$ & \multicolumn{2}{|c|}{$1851 \pm 64^{\mathrm{A}}$} & $2153 \pm 75^{A}$ & \multicolumn{2}{|c|}{$1108 \pm 75^{C}$} \\
\hline & 5-day fasting & $1211 \pm 64^{\mathrm{D}}$ & \multicolumn{2}{|c|}{$1640 \pm 64^{B}$} & $1902 \pm 75^{B}$ & \multicolumn{2}{|c|}{$949 \pm 75^{\mathrm{D}}$} \\
\hline & & \multicolumn{6}{|c|}{ Final weight at sampling, $g$} \\
\hline & & \multicolumn{6}{|c|}{ Sex $\times$ feeding intensity interaction } \\
\hline & & \multicolumn{3}{|c|}{ Male } & \multicolumn{3}{|c|}{ Female } \\
\hline & & LFI & \multicolumn{2}{|c|}{ HFI } & LFI & \multicolumn{2}{|c|}{ HFI } \\
\hline & Body weight & $1770 \pm 78^{B}$ & \multicolumn{2}{|c|}{$2338 \pm 78^{A}$} & $909 \pm 78^{D}$ & \multicolumn{2}{|c|}{$1168 \pm 78^{C}$} \\
\hline & Liver weight & $41.9 \pm 1.7^{\mathrm{B}}$ & \multicolumn{2}{|c|}{$55.1 \pm 1.7^{\mathrm{A}}$} & $25.2 \pm 1.7^{\mathrm{D}}$ & \multicolumn{2}{|c|}{$30.9 \pm 1.7^{c}$} \\
\hline & & \multicolumn{6}{|c|}{ Sex $\times$ diet interaction } \\
\hline & & \multicolumn{3}{|c|}{ Male } & & Female & \\
\hline & & Herring oil & Soya oil & Canola oil & Herring oil & Soya oil & Canola oil \\
\hline Body weight & Control & $2504 \pm 106^{\mathrm{A}^{*}}$ & $2117 \pm 106^{B}$ & $1999 \pm 106^{B}$ & $1085 \pm 106^{C}$ & $1155 \pm 106^{C}$ & $1143 \pm 106^{C}$ \\
\hline & Fasted & $1867 \pm 106^{\mathrm{A}}$ & $1884 \pm 106^{A}$ & $1954 \pm 106^{A}$ & $1025 \pm 106^{\mathrm{B}}$ & $928 \pm 106^{B}$ & $895 \pm 106^{B}$ \\
\hline Liver weight & Control & $54.7 \pm 2.4^{\mathrm{A}^{*}}$ & $45.6 \pm 2.4^{B}$ & $44.8 \pm 2.4^{B}$ & $27.6 \pm 2.4^{C}$ & $27.4 \pm 2.4^{C}$ & $28.7 \pm 2.4^{C}$ \\
\hline & Fasted & $47.0 \pm 2.4^{\mathrm{A}}$ & $48.3 \pm 2.4^{\mathrm{A}}$ & $49.5 \pm 2.4^{\mathrm{A}}$ & $30.4 \pm 2.4^{B}$ & $27.3 \pm 2.4^{B}$ & $26.8 \pm 2.4^{B}$ \\
\hline
\end{tabular}

Values are Ismeans \pm SEM. For feeding trial weights, labeled means with no common letters differ within sex and feeding intensity, and means with * differ between feeding intensity within sex $(P \leq 0.05)$. For 5 -day fasting group weights, labeled means with no common letters differ within treatment response. For final body and liver weights, labeled means with no common letters differ within fasting treatments, and means with * differ between fasting treatments. High feeding intensity, HFI; low feeding intensity, LFI.

These BW distinctions remained after the fasting period and at final sampling. The difference in the final BW revealed the fasted mink to be generally lighter than the controls, with heavier males in the $\mathrm{HO}$ group.

\section{Liver health}

Liver lipid\% was higher in the fasted mink, and it was the highest in the mink fed at the HFI (Table 5). A significant interaction between diet and FI was observed, with the highest liver lipid levels in the mink fed the SO and $\mathrm{CO}$ diets at the HFI, and the lowest in the mink fed the SO diet at the LFI, which did not differ significantly from the $\mathrm{HO}$ groups (Table 6). Liver weights were higher in the males than females, and within sex higher in the HFI groups. No differences were observed in the females with regard to diet or fasting in liver weight; however, in the males, the heaviest livers were found in the control $\mathrm{HO}$ group, and their average liver weights were higher than those of the fasted $\mathrm{HO}$ group and the control SO and CO mink. HSI was greater in the females (females: $2.76 \pm 0.06$, males: $2.38 \pm 0.06$ ), and an overall higher HSI was observed in the fasted mink (control: $2.37 \pm$ 0.08 , fasted: $2.77 \pm 0.08$ ). The mink of the LFI HO group had the highest HSI, which did not differ from the HFI SO group or the LFI and HFI CO groups.

\section{Clinical chemistry and endocrinology}

Blood glucose levels were the highest at the start of the feeding trial (September: $4.6 \pm 0.1$, October: $3.8 \pm 0.1$, November $3.7 \pm 0.1 \mathrm{mmol} / \mathrm{L})$. The final glucose concentrations, analyzed on plasma, were higher in the control mink, and within the fasted mink they were higher in the HFI group (Table 5). The fasted mink had higher plasma ALT activities (control: $139 \pm 22$, fasted: $299 \pm 22 \mathrm{U} / \mathrm{L}$ ). Plasma AKPH activities were higher in the fasted mink fed at the LFI compared to the HFI, but did not differ from the controls. 
Table 5 Effect of fasting and feeding intensity on liver lipid\%, plasma glucose, AKPH, and LDL-cholesterol

\begin{tabular}{|c|c|c|c|c|}
\hline & \multicolumn{2}{|c|}{ Control } & \multicolumn{2}{|c|}{ Fasted } \\
\hline & LFI & HFI & LFI & $\mathrm{HFI}$ \\
\hline Liver Lipids, \% & $5.9 \pm 1.1^{C}$ & $6.6 \pm 1.1^{C}$ & $16.2 \pm 1.1^{\mathrm{B}}$ & $21.7 \pm 1.1^{\mathrm{A}}$ \\
\hline Glucose, $\mathrm{mmol} / \mathrm{L}$ & $8.3 \pm 0.3^{\mathrm{A}}$ & $8.5 \pm 0.3^{\mathrm{A}}$ & $6.5 \pm 0.3^{C}$ & $7.6 \pm 0.3^{B}$ \\
\hline $\mathrm{AKPH}, \mathrm{U} / \mathrm{L}$ & $22 \pm 3^{A B}$ & $21 \pm 3^{A B}$ & $29 \pm 3^{A}$ & $17 \pm 3^{B}$ \\
\hline LDL-Cholesterol, mmol/L & $0.58 \pm 0.03^{A}$ & $0.41 \pm 0.03^{B}$ & $0.28 \pm 0.03^{C}$ & $0.26 \pm 0.03^{C}$ \\
\hline
\end{tabular}

Values are Ismeans \pm SEM. Labeled means with no common letters differ within the response variable $(P \leq 0.05)$. Alkaline phosphatase, AKPH; high feeding intensity, HFl; low-density lipoprotein, LDL; low feeding intensity, LFI.

In the control groups, LDL-cholesterol was higher in the mink fed at the LFI than the HFI, and the levels were lower in the fasted mink where no effect of FI was found (Table 5). HDL-cholesterol was lower in the fasted mink $(3.64 \pm 0.08$ vs. $3.32 \pm 0.08 \mathrm{mmol} / \mathrm{L})$, and the levels were also affected by FI and diet; the highest HDL-cholesterol levels were in the mink fed the SO diet at the LFI, with no differences among the other groups (Table 7). LDLand HDL-cholesterol both showed a significant diet and sex interaction, with LDL-cholesterol being higher in the males fed the $\mathrm{CO}$ diet and the females fed the $\mathrm{HO}$ diet. The highest HDL-cholesterol levels were observed in the females fed the SO diet and the males fed the $\mathrm{CO}$ diet, and for both sexes the lowest concentrations were observed when fed the HO diet. Plasma FFA levels did not differ among the controls and were higher in the fasted mink, with the highest levels observed in the fasted LFI CO group (Table 8). Higher TAG levels were noted in the fasted mink, with the exception of the mink fed the SO diet at the HFI. Additionally, the males had lower TAG levels than the females $(0.94 \pm 0.04$ vs. $1.13 \pm$ $0.04 \mathrm{mmol} / \mathrm{L}$ ).

Insulin levels were lower in the males than females $(4.32 \pm 0.35 v s$. $5.98 \pm 0.35 \mu \mathrm{U} / \mathrm{mL})$, the mink fed at the HFI had higher insulin levels than those fed at the LFI $(5.67 \pm 0.36$ vs. $4.63 \pm 0.36 \mu \mathrm{U} / \mathrm{mL})$, and the concentrations correlated significantly with the body fat\% (\%BF; $\left.r_{p}=0.26, P=0.028\right)$. Overall, the fasted mink had lower insulin levels $(4.34 \pm 0.36 v s$. $5.95 \pm 0.36 \mu \mathrm{U} / \mathrm{mL})$. Leptin levels in the control mink were higher when fed at the HFI $(3.41 \pm 0.19 \mathrm{ng} / \mathrm{mL})$ compared to the LFI $(1.91 \pm$ $0.19 \mathrm{ng} / \mathrm{mL})$ and correlated with $\% \mathrm{BF}\left(\mathrm{r}_{\mathrm{p}}=0.58, \mathrm{P}=\right.$ 0.001). In the fasted mink, leptin levels were lower than in the controls and did not differ between the FI groups (LFI: $1.25 \pm 0.19$, HFI: $1.36 \pm 0.19 \mathrm{ng} / \mathrm{mL}$ ). $\mathrm{T}_{3}$ tended to be higher in the mink fed at the HFI, correlated with \% $\mathrm{BF}\left(\mathrm{r}_{\mathrm{p}}=0.60, \mathrm{P}=0.001\right)$, and was lower in the fasted mink (Table 9). $\mathrm{T}_{4}$ did not correlate with $\% \mathrm{BF}\left(\mathrm{r}_{\mathrm{p}}=0.36\right.$, $\mathrm{P}=0.77$ ). $\mathrm{T}_{4}$ levels differed significantly depending on the FI of the HO mink (LFI: $10.2 \pm 0.8$, HFI: $13.1 \pm$ $0.8 \mathrm{nmol} / \mathrm{L}$ ) but there were no other significant differences within diets or FI (SO; LFI: $11.7 \pm 0.8$, HFI: $10.0 \pm$ 0.8, CO; LFI: $11.8 \pm 0.8$, HFI: $10.6 \pm 0.8 \mathrm{nmol} / \mathrm{L})$.

\section{Discussion}

By modifying the FI, we created two distinct BW groups of lighter and heavier mink. Dietary fat source also influenced the BW of the mink, as observed previously by Käkelä et al. [18]. According to our results, the control males fed the HO diet were significantly heavier than the males fed the $\mathrm{SO}$ or $\mathrm{CO}$ diets. This difference was possibly caused by the increased feed intake in the $\mathrm{HO}$ males.

Fasting expectedly caused weight loss and it is known to result in the development of fatty liver in carnivores $[3-5,25]$. A 5\% liver TAG threshold is used for the diagnosis of fatty liver in cats [26]. Using this threshold, the results of previous studies examining both hepatic TAG and total lipid levels in mink suggest that the corresponding total liver lipid level threshold for fatty liver in mink would be between 9 to $12 \%[3,18]$. Based on this threshold range, the control mink appeared to have healthy hepatic lipid levels. With fasting, hepatic lipid levels increased, exceeding 12\%, along with plasma ALT activities, an indicator of liver dysfunction [27]. Higher liver lipid values in the mink fed at the HFI compared to

Table 6 Effect of the herring oil, soya oil, and canola oil experimental diets and feeding intensity on mink liver lipid\%, liver weight, and HSI

\begin{tabular}{|c|c|c|c|c|c|c|}
\hline & \multicolumn{3}{|c|}{ LFI } & \multicolumn{3}{|c|}{ HFI } \\
\hline & Herring oil & Soya oil & Canola oil & Herring oil & Soya oil & Canola oil \\
\hline Liver Lipids, \% & $11.7 \pm 1.3^{B C}$ & $8.9 \pm 1.3^{C}$ & $12.7 \pm 1.3^{\mathrm{AB}}$ & $12.0 \pm 1.3^{B C}$ & $15.7 \pm 1.3^{\mathrm{A}}$ & $14.7 \pm 1.3^{\mathrm{A}}$ \\
\hline Liver Weight, $g$ & $37.0 \pm 1.7^{\mathrm{B}}$ & $30.4 \pm 1.7^{C}$ & $33.2 \pm 1.7^{\mathrm{BC}}$ & $42.9 \pm 1.7^{\mathrm{A}}$ & $44.4 \pm 1.7^{\mathrm{A}}$ & $41.7 \pm 1.7^{\mathrm{A}}$ \\
\hline HSI & $2.74 \pm 0.09^{A}$ & $2.42 \pm 0.09^{C}$ & $2.70 \pm 0.09^{\mathrm{AB}}$ & $2.43 \pm 0.09^{B C}$ & $2.61 \pm 0.09^{\mathrm{ABC}}$ & $2.52 \pm 0.09^{\mathrm{ABC}}$ \\
\hline
\end{tabular}

Values are Ismeans \pm SEM. Labeled means with no common letters differ within the response variable $(\mathrm{P} \leq 0.05)$. Hepato-somatic index, HSl; high feeding intensity, HFI; low feeding intensity, LFI. 
Table 7 Effect of feeding intensity, sex, and the herring oil, soya oil, and canola oil experimental diets on plasma LDL- and HDL-cholesterol levels

\begin{tabular}{|c|c|c|c|c|c|c|}
\hline & \multicolumn{6}{|c|}{ Feeding intensity $\times$ diet interaction } \\
\hline & \multicolumn{3}{|c|}{ LFI } & \multicolumn{3}{|c|}{ HFI } \\
\hline & Herring oil & Soya oil & Canola oil & Herring oil & Soya oil & Canola oil \\
\hline \multirow[t]{4}{*}{$\mathrm{HDL}$-Cholesterol, $\mathrm{mmol} / \mathrm{L}$} & $3.35 \pm 0.12^{B}$ & $4.05 \pm 0.12^{A}$ & $3.52 \pm 0.12^{B}$ & $3.13 \pm 0.12^{B}$ & $3.22 \pm 0.12^{B}$ & $3.51 \pm 0.12^{B}$ \\
\hline & \multicolumn{6}{|c|}{ Sex $\times$ diet interaction } \\
\hline & \multicolumn{3}{|c|}{ Male } & \multicolumn{3}{|c|}{ Female } \\
\hline & Herring oil & Soya oil & Canola oil & Herring oil & Soya oil & Canola oil \\
\hline LDL-Cholesterol, $\mathrm{mmol} / \mathrm{L}$ & $0.35 \pm 0.04^{\mathrm{AB}}$ & $0.34 \pm 0.04^{B}$ & $0.44 \pm 0.04^{\mathrm{A}}$ & $0.44 \pm 0.04^{\mathrm{A}}$ & $0.39 \pm 0.04^{\mathrm{AB}}$ & $0.34 \pm 0.04^{B}$ \\
\hline HDL-Cholesterol, $\mathrm{mmol} / \mathrm{L}$ & $2.97 \pm 0.13^{\mathrm{D}}$ & $3.27 \pm 0.13^{C D}$ & $3.45 \pm 0.13^{B C}$ & $3.51 \pm 0.13^{B C}$ & $4.01 \pm 0.13^{\mathrm{A}}$ & $3.58 \pm 0.13^{B}$ \\
\hline
\end{tabular}

Values are Ismeans \pm SEM. Labeled means with no common letters differ within the response variable $(P \leq 0.05)$. High-density lipoprotein, $\mathrm{HDL} ;$ high feeding intensity, HFI; low-density lipoprotein, LDL; low feeding intensity, LFI.

the LFI revealed the negative implications of excessive adiposity on liver health. The severity of the hepatic lipid accumulation in the mink fed at the HFI was lower when the mink were fed the $\mathrm{HO}$ diet compared to the $\mathrm{SO}$ and $\mathrm{CO}$ diets, suggesting that $\mathrm{n}-3$ long-chain PUFA may help ameliorate or slow the development of fatty liver in over-conditioned mink. The HSI results were not in agreement with the liver lipid\%, unlike in a previous study [3]. Caution is needed when using HSI, as in the current study it was possible for lean mink without fatty liver to have higher HSI values than heavier mink with fatty liver.

Fasting causes lipolysis in body fat depots releasing fatty acids, and the liver may increase its fatty acid uptake from the blood in proportion to their concentration in circulation [12]. Plasma FFA levels were not affected by dietary treatment in the controls. Similar to previous studies [3,5], the FFA and TAG levels increased with fasting and the FFA levels were higher in the mink with higher liver lipid levels, with the exception of the mink fed the HO diet at the LFI. These results reflect the rapid mobilization of the body fat reserves [3], and are also observed in clinical cases of feline hepatic lipidosis [28]. An exception to this was the mink fed the SO diet at the HFI, where the high dietary n-6:n-3 PUFA ratio may decrease the liver secretion of TAG [29], contributing to the increased liver lipid content in these mink. The decreased secretion may also explain the lack of response to fasting compared to the other groups.

Plasma LDL-cholesterol levels were lower in the fasted and HFI groups, differing from Mustonen et al. [5] where fasting did not have an effect. Ibrahim et al. [30] reported increased LDL-cholesterol levels in cats with diet-induced obesity. No clear explanations are apparent for these differences in LDL-cholesterol. Decreases in HDL-cholesterol in the fasted mink are in agreement with Mustonen et al. [5], and could be related to increased clearance by the liver [30]. Whether this is a result of fasting or a consequence of fatty liver is not known, and no changes were evident in clinical cases of feline hepatic lipidosis [28].

Insulin resistance and hyperglycemia are associated with fatty liver, with the development of the two being able to further worsen each other [10]. Monthly blood glucose concentrations were within the normal range for mink [31], which differs from a previous study where high FI was associated with hyperglycemia [9]. The final plasma glucose values were elevated slightly in the control mink, but the results are difficult to interpret as handling stress and ketamine can also increase the blood glucose levels [32]. In the fasting model, mink maintain

Table 8 Effect of the herring oil, soya oil, and canola oil experimental diets, LFI and HFI, and fasting on mink plasma levels of FFA and TAG

\begin{tabular}{|c|c|c|c|c|c|}
\hline & & \multicolumn{2}{|c|}{$\mathrm{FFA}, \mathrm{mmol} / \mathrm{L}$} & \multicolumn{2}{|c|}{ TAG, $\mathrm{mmol} / \mathrm{L}$} \\
\hline & & Control & Fasted & Control & Fasted \\
\hline \multirow[t]{2}{*}{ Herring oil } & LFI & $0.50 \pm 0.14^{*}$ & $1.32 \pm 0.14^{\mathrm{ABC}}$ & $0.94 \pm 0.09^{\mathrm{AB}^{*}}$ & $1.31 \pm 0.09^{\mathrm{A}}$ \\
\hline & $\mathrm{HFI}$ & $0.58 \pm 0.14$ & $0.95 \pm 0.14^{c}$ & $0.89 \pm 0.0^{A B^{*}}$ & $1.34 \pm 0.09^{\mathrm{A}}$ \\
\hline \multirow[t]{2}{*}{ Soya oil } & LFI & $0.44 \pm 0.14^{*}$ & $0.96 \pm 0.14^{C}$ & $0.72 \pm 0.09^{\mathrm{B}^{*}}$ & $1.15 \pm 0.09^{\mathrm{AB}}$ \\
\hline & $\mathrm{HFI}$ & $0.46 \pm 0.14^{*}$ & $1.52 \pm 0.14^{\mathrm{AB}}$ & $1.06 \pm 0.09^{A}$ & $1.02 \pm 0.09^{B}$ \\
\hline \multirow[t]{2}{*}{ Canola oil } & LFI & $0.60 \pm 0.14^{*}$ & $1.63 \pm 0.14^{\mathrm{A}}$ & $0.76 \pm 0.09^{\mathrm{B}^{*}}$ & $1.11 \pm 0.09^{\mathrm{AB}}$ \\
\hline & $\mathrm{HFI}$ & $0.57 \pm 0.14^{*}$ & $1.10 \pm 0.14^{\mathrm{ABC}}$ & $0.85 \pm 0.09^{A B^{*}}$ & $1.25 \pm 0.09^{\mathrm{AB}}$ \\
\hline
\end{tabular}

Values are Ismeans \pm SEM. Labeled means with no common letters differ within the response variable column, and means with *differ within the response variable row $(\mathrm{P} \leq 0.05)$. Free fatty acids, FFA; high feeding intensity, HFI; low feeding intensity, LFl; triacylglycerols, TAG. 
Table 9 Effect of fasting and feeding intensity combined with the herring oil, soya oil, and canola oil experimental diets on $\mathrm{T}_{3}$ concentrations

\begin{tabular}{|c|c|c|c|c|c|}
\hline & & \multicolumn{4}{|c|}{$\mathrm{T}_{3}, \mathrm{nmol} / \mathrm{L}$} \\
\hline & & \multicolumn{2}{|c|}{ Fasting treatment } & \multicolumn{2}{|c|}{ Feeding intensity } \\
\hline & & Control & Fasted & LFI & HFI \\
\hline \multirow[t]{2}{*}{ Herring oil } & Male & $0.81 \pm 0.05^{c^{*}}$ & $0.65 \pm 0.05^{C}$ & $0.65 \pm 0.06^{\mathrm{B}^{*}}$ & $0.82 \pm 0.06^{C}$ \\
\hline & Female & $0.98 \pm 0.05^{A B^{*}}$ & $0.85 \pm 0.06^{\mathrm{AB}}$ & $0.73 \pm 0.06^{A B^{*}}$ & $1.10 \pm 0.06^{\mathrm{A}}$ \\
\hline \multirow[t]{2}{*}{ Soya oil } & Male & $0.86 \pm 0.05^{\mathrm{BC}}$ & $0.70 \pm 0.05^{B C}$ & $0.65 \pm 0.06^{\mathrm{B}^{*}}$ & $0.91 \pm 0.06^{B C}$ \\
\hline & Female & $1.07 \pm 0.05^{\mathrm{A}^{*}}$ & $0.71 \pm 0.06^{\mathrm{BC}}$ & $0.85 \pm 0.06^{A}$ & $0.94 \pm 0.06^{B C}$ \\
\hline \multirow[t]{2}{*}{ Canola oil } & Male & $0.83 \pm 0.05^{c^{*}}$ & $0.70 \pm 0.05^{B C}$ & $0.69 \pm 0.06^{B^{*}}$ & $0.84 \pm 0.06^{C}$ \\
\hline & Female & $0.92 \pm 0.05^{\mathrm{BC}}$ & $0.93 \pm 0.07^{\mathrm{A}}$ & $0.78 \pm 0.06^{\mathrm{AB}}$ & $1.07 \pm 0.07^{\mathrm{AB}}$ \\
\hline
\end{tabular}

Values are Ismeans \pm SEM. Labeled means with no common letters differ within the response variable column and means with *differ within the response variable row $(\mathrm{P} \leq 0.05)$. High feeding intensity, HFl; low feeding intensity, $\mathrm{LFI}$; triiodothyronine, $\mathrm{T}_{3}$.

normoglycemia [5], and do not develop the severe derangement of glucose regulation that can be observed in nursing sickness in mink [33] and in feline hepatic lipidosis [28]. Insulin concentrations were not elevated either, and decreased during fasting, helping to spare glucose and increase fat mobilization $[3,24]$. Although the mink appear to have remained normoglycemic throughout the study, the positive correlation between insulin and \%BF suggests that long-term monitoring of blood glucose concentrations may be interesting as there is evidence for impaired glycemic control in over-conditioned mink [9].

Under normal physiological conditions, plasma leptin levels in mink increase with increasing BW [34], and decrease during fasting $[3,24]$. This relationship between body fat and leptin levels was maintained in the control mink. However, the effect of body condition on leptin levels was not present in the fasted mink, with similar levels in the LFI and HFI groups, indicating that fasting has a stronger influence on leptin levels than adiposity. Although higher leptin levels are observed in clinical cases of feline hepatic lipidosis [28], they are likely to be related to increased adiposity. Regarding the $\mathrm{T}_{3}$ concentrations, a clear decrease was observed in the fasted mink. This was documented also previously [24] and probably represents an adaptation of energy saving.

The balance of lipid delivery and metabolism in the liver contributes to the net hepatic lipid accumulation. Obesity may aggravate the problem by increasing the amount of fat available for mobilization. Dietary fat may also influence lipid metabolism in the liver, with long-chain n-3 PUFA promoting hepatic lipid excretion and oxidation [29]. Ahlstrøm and Skrede [35] found a positive effect of fish oil, high in long-chain n-3 PUFA, on hepatic metabolism, with dietary levels correlating positively to liver peroxisomal $\beta$-oxidation activity. During periods of hepatic lipid accumulation, it would be beneficial to be able to increase fatty acid oxidation within the liver. This may help to explain why within the over-conditioned HFI group, the mink fed the HO diet had the lowest liver lipid levels.
In addition, the beneficial role of $\mathrm{HO}$ could potentially be attributed to the higher levels of long-chain monounsaturated fatty acids, also shown to increase oxidative capacity of liver and muscle [36]. A longer-term controlled feeding experiment, accounting for the seasonal fluctuations in body condition, with a larger number of mink per subtreatment, would be necessary to confirm the potential beneficial effects of dietary long-chain n-3 PUFA on liver health.

Despite the significant hepatic lipid accumulation as a result of fasting, the mink appeared alert and healthy. It remains unknown what can cause the relatively benign lipid accumulation to progress rapidly to the life-threatening stage in hypercarnivores, such as mink and cats $[1,6]$. Currently there are also no specific pharmaceutical therapies available. It is therefore evident that preventing the overfeeding and rapid slimming of mink throughout the year may help maintain liver health. It is noteworthy that the current RDA guidelines, used in this study [21], may exceed the mink's energy requirements leading to obesity. The HFI mink consumed just over 100\% RDA of what was offered but were still over-conditioned.

To conclude, by feeding the mink different dietary fat sources at the LFI and HFI we were able to examine the effects of FI and fatty acid nutrition on the development of fasting-induced fatty liver. FI had no effect on the hepatic lipid content of the control mink, whereas fasting caused the development of fatty liver in the mink with increasing severity in those fed at the HFI. Preventing over-conditioning and increasing dietary intake of long-chain n-3 PUFA were found to be beneficial in decreasing the severity of lipid accumulation.

\section{Additional files}

Additional file 1: P-values of the main effects and interactions for mink body weights, feed intake, and blood glucose during the feeding trial from September to November. 
Additional file 2: P-values of the main effects and interactions for final body weight and liver responses.

Additional file 3: P-values of the main effects and interactions for the mink clinical chemistry and endocrinological responses.

\section{Abbreviations}

ALT: Alanine transaminase; AKPH: Alkaline phosphatase; \%BF: Body fat\%; BW: Body weight; CO: Canola oil; FI: Feeding intensity; FFA: Free fatty acid; HSI: Hepato-somatic index; HO: Herring oil; HDL: High-density lipoprotein; HFI: High feeding intensity; LDL: Low-density lipoprotein; LFI: Low feeding intensity; PUFA: Polyunsaturated fatty acid; RDA: Recommended dietary allowance; SO: Soya oil; $\mathrm{T}_{4}$ : Thyroxine; TAG: Triacylglycerols;

$\mathrm{T}_{3}$ : Triiodothyronine.

\section{Competing interests}

The authors declare that they have no competing interests.

\section{Authors' contributions}

MFD, A-MM, PN, KR-W designed the research. MFD, JH, SL, A-MM, PN, KR-W conducted research. MFD analyzed data and led the writing of the paper. MFD and KR-W share primary responsibility for final content. All authors read and approved the final manuscript.

\section{Acknowledgements}

We wish to acknowledge the skillful technical assistance of Lora Harris, Jennifer Dobson, and Jessicca Fielding; the staff of the Canadian Centre for Fur Animal Research, Rae Maclnnis, Annette Murphy, and Cindy Crossman; Mrs. Rauni Kojo for her help in the laboratory analyses, and Dr. Tess Astatkie for statistical guidance. This project has been funded in part by Natural Sciences and Engineering Research Council of Canada (Discovery Grant to KR-W), Agriculture and Agri-Food Canada, Canada Mink Breeders' Association, Fur Commission USA, the Heger Company, and the Chinese Ministry of Education (travel stipend to SL).

\section{Author details}

${ }^{1}$ Department of Plant and Animal Sciences, Faculty of Agriculture, Dalhousie University, P.O. Box 550, B2N 5E3 Truro, NS, Canada. ${ }^{2}$ Department of Bioscience and Biotechnology, Dalian University of Technology, 116024 Dalian, China. ${ }^{3}$ Institute of Biomedicine/Anatomy, School of Medicine, Faculty of Health Sciences, University of Eastern Finland, P.O. Box 1627, FI-70211 Kuopio, Finland. ${ }^{4}$ Department of Biology, Faculty of Science and Forestry, University of Eastern Finland, P.O. Box 111, Fl-80101 Joensuu, Finland.

Received: 6 September 2013 Accepted: 9 January 2014

Published: 16 January 2014

\section{References}

1. Hunter B, Lemieux N: Mink ... Biology, Health and Disease. Guelph, Canada: University of Guelph Graphic and Print Services; 1996.

2. Rouvinen-Watt K: Nursing sickness in the mink - a metabolic mystery or a familiar foe? Can J Vet Res 2003, 67:161-168.

3. Rouvinen-Watt K, Mustonen A-M, Conway R, Pal C, Harris L, Saarela S, Strandberg U, Nieminen P: Rapid development of fasting-induced hepatic lipidosis in the American mink (Neovison vison): Effects of food deprivation and re-alimentation on body fat depots, tissue fatty acid profiles, hematology and endocrinology. Lipids 2010, 45:111-128.

4. Nieminen P, Mustonen A-M, Kärjä V, Asikainen J, Rouvinen-Watt K: Fatty acid composition and development of hepatic lipidosis during food deprivation-mustelids as a potential animal model for liver steatosis. Exp Biol Med 2009, 234:278-286.

5. Mustonen A-M, Pyykönen T, Paakkonen T, Ryökkynen A, Asikainen J, Aho J, Mononen J, Nieminen P: Adaptations to fasting in the American mink (Mustela vison): carbohydrate and lipid metabolism. Comp Biochem Physiol A 2005, 140:195-202.

6. Armstrong PJ, Blanchard G: Hepatic lipidosis in cats. Vet Clin North Am Small Anim Pract 2009, 39:599-616.

7. Dimski DS, Taboada J: Feline idiopathic hepatic lipidosis. Vet Clin North Am Small Anim Pract 1995, 25:357-373.

8. York LW, Puthalapattu S, Wu GY: Nonalcoholic fatty liver disease and low-carbohydrate diets. Annu Rev Nutr 2009, 29:365-379.
9. Rouvinen-Watt K, Murphy J, Chan C: Effect of feeding intensity on body condition and glycemic control in mink Mustela vison. Scientifur 2004, 28:129-135.

10. Marceau P, Biron S, Hould F-S, Marceau S, Simard S, Thung SN, Kral JG: Liver pathology and the metabolic syndrome $\mathrm{X}$ in severe obesity. J Clin Endocrinol Metab 1999, 84:1513-1517.

11. Jensen MD, Haymond MW, Rizza RA, Cryer PE, Miles JM: Influence of body fat distribution on free fatty acid metabolism in obesity. J Clin Invest 1989, 83:1 168-1173.

12. Bradbury MW: Lipid metabolism and liver inflammation. I. Hepatic fatty acid uptake: possible role in steatosis. Am J Physiol Gastrointest Liver Physiol 2006, 290:G194-G198.

13. Araya J, Rodrigo R, Videla L, Thielemann L, Orellana M, Pettinelli P, Poniachik $\mathrm{J}$ : Increase in long-chain polyunsaturated fatty acid $n-6 / n-3$ ratio in relation to hepatic steatosis in patients with non-alcoholic fatty liver disease. Clin Sci 2004, 106:635-643.

14. Lindén D, Lindberg K, Oscarsson J, Claesson C, Asp L, Li L, Gustafsson M, Borén J, Olofsson S-O: Influence of peroxisome proliferator-activated receptor a agonists on the intracellular turnover and secretion of apolipoprotein (Apo) B-100 and ApoB-48. J Biol Chem 2002, 277:23044-23053.

15. Levy JR, Clore JN, Steven W: Dietary n-3 polyunsaturated fatty acids decrease hepatic triglycerides in Fischer 344 rats. Hepatology 2004, 38:608-616.

16. Alwayn IPJ, Gura K, Nosé V, Zausche B, Javid P, Garza J, Verbesey J, Voss S, Ollero M, Andersson C, Bistrian B, Folkman J, Puder M: Omega-3 fatty acid supplementation prevents hepatic steatosis in a murine model of nonalcoholic fatty liver disease. Pediatr Res 2005, 57:445-452.

17. Capanni M, Calella F, Biagini MR, Genise S, Raimondi L, Bedogni G, SvegliatiBaroni G, Sofi F, Milani S, Abbate R, Surrenti C, Casini A: Prolonged n-3 polyunsaturated fatty acid supplementation ameliorates hepatic steatosis in patients with non-alcoholic fatty liver disease: a pilot study. Aliment Pharmacol Ther 2006, 23:1143-1151.

18. Käkelä R, Pölönen I, Miettinen $M$, Asikainen J: Effects of different fat supplements on growth and hepatic lipids and fatty acids in male mink. Acta Agric Scand Sect A, Animal Sci 2001, 51:217-223.

19. Clausen TN, Sandbøl P: Fasting of male mink after mating. Influence on liver fat and blood ketone content. Akureyri, Iceland: Proceedings of the Nordic Association of Agricultural Scientists Seminar; 2006.

20. Canadian Council on Animal Care: Guide to the Care and Use of Experimental Animals. Ottawa, Canada: Canadian Council on Animal Care; 1993.

21. Rouvinen-Watt K, White MB, Campbell R: Mink Feeds and Feeding. Ottawa, Canada: Ontario Ministry of Agriculture and Food and Truro, Canada: Nova Scotia Agricultural College; 2005.

22. Nieminen $P$, Käkelä $R$, Pyykönen T, Mustonen A-M: Selective fatty acid mobilization in the American mink (Mustela vison) during food deprivation. Comp Biochem Physiol B 2006, 145:81-93.

23. Folch J, Lees M, Sloane Stanley GH: A simple method for the isolation and purification of total lipides from animal tissues. J Biol Chem 1957, 226:497-509.

24. Mustonen A-M, Saarela S, Pyykönen T, Nieminen P: Endocrinologic adaptations to wintertime fasting in the male American mink (Mustela vison). Exp Biol Med 2005, 230:612-620.

25. Szabo J, Ibrahim WH, Sunvold GD, Dickey KM, Rodgers JB, Toth IE, Boissonneault GA, Bruckner GG: Influence of dietary protein and lipid on weight loss in obese ovariohysterectomized cats. Am J Vet Res 2000, 61:559-565.

26. Pazak HE, Bartges JW, Cornelius LC, Scott MA, Gross K, Huber TL: Characterization of serum lipoprotein profiles of healthy, adult cats and idiopathic feline hepatic lipidosis patients. J Nutr 1998, 128:2747S-2750S.

27. Giannini EG, Testa R, Savarino V: Liver enzyme alteration: $A$ guide for clinicians. CMAJ 2005, 172:367-379.

28. Mazaki-Tovi M, Abood SK, Segev G, Schenck PA: Alterations in adipokines in feline hepatic lipidosis. J Vet Intern Med 2013, 27:242-249.

29. El-Badry AM, Graf R, Clavien P-A: Omega 3 - Omega 6: What is right for the liver? J Hepatol 2007, 47:718-725.

30. Ibrahim WH, Szabo J, Sunvold GD, Kelleher JK, Bruckner GG: Effect of dietary protein quality and fatty acid composition on plasma lipoprotein concentrations and hepatic triglyceride fatty acid synthesis in obese cats undergoing rapid weight loss. Am J Vet Res 2000, 61:566-572.

31. Hynes AMJ, Rouvinen-Watt $\mathrm{K}$ : Monitoring blood glucose levels in female mink during the reproductive cycle: 1 . Prevention of hyperglycemia during the nursing period. Can J Vet Res 2007, 71:241-248. 
32. Hsu WH, Hembrough FB: Intravenous glucose tolerance test in cats: influenced by acetylpromazine, ketamine, morphine, thiopental, and xylazine. Am J Vet Res 1982, 43:2060-2061.

33. Wamberg $\mathrm{S}$, Clausen TN, Olesen CR, Hansen O: Nursing sickness in lactating mink (Mustela vison) II. Pathophysiology and changes in body fluid composition. Can J Vet Res 1992, 56:95-101.

34. Tauson A-H, Forsberg M, Chwalibog A: Plasma concentrations of leptin mirror changes in body weight but do not influence the pattern of preovulatory luteinizing hormone surge in mink (Mustela vison). J Nutr 2002, 132:1790S-1792S.

35. Ahlstrøm $\varnothing$, Skrede A: Liver fatty acid composition and peroxisomal fatty acid oxidase activity in blue foxes (Alopex lagopus) and mink (Mustela vison) fed diets containing different levels of fish oil. Comp Biochem Physiol A 1997, 117:135-140.

36. Yang Z-H, Miyahara H, Mori T, Doisaki N, Hatanaka A: Beneficial effects of dietary fish-oil-derived monounsaturated fatty acids on metabolic syndrome risk factors and insulin resistance in mice. J Agric Food Chem 2011, 59:7482-7489.

doi:10.1186/1751-0147-56-5

Cite this article as: Dick et al:: High feeding intensity increases the severity of fatty liver in the American mink (Neovison vison) with potential ameliorating role for long-chain $n-3$ polyunsaturated fatty acids. Acta Veterinaria Scandinavica 2014 56:5.

\section{Submit your next manuscript to BioMed Central and take full advantage of:}

- Convenient online submission

- Thorough peer review

- No space constraints or color figure charges

- Immediate publication on acceptance

- Inclusion in PubMed, CAS, Scopus and Google Scholar

- Research which is freely available for redistribution 